\title{
Research on Stock Market Volatility
}

\author{
Ting Liu \\ $\mathrm{PhD}$ Student \\ School of Economics \\ Central University of Finance and Economics \\ Xiaoying Huang, PhD \\ China Minsheng Bank
}

\begin{abstract}
In the financial market, the stock market has a very important position, the status of the stock market influence and reflect a country's level of economic development and the stable state, so the stock market price and income volatility has been the focus of research scholars. Based on the early efficient market theory, the stock market price fluctuation in the financial market is random and there are no rules to follow. All the information is reflected in the price. But along with the continuous development of empirical research, found that the stock market index is not random, in theory, because the market itself is not fully effective, the information can't be fully reflected in the price. So the stock market price fluctuations have regularity and some unique characteristics, in this paper, the data source is Shanghai composite index 2007/12/31-2018/3/28 stock closing price, trying to study volatility characteristics of China's stock prices and yields, found that yield a wave agglomeration and long memory, and volatility is affected by the policy and global economic conditions, and provide policy Suggestions to perfect the financial supervision and regulation.
\end{abstract}

Keywords: Closing price, Stock returns, Volatility characteristics

\section{Introduction}

The stock market is filled with various sources of capital, reflecting the development status and prospects of different industries, regions, enterprises and even the whole country in a country. From a macro level, the government and regulators keep mountain to aunt management and supervision of the market, to ensure that the domestic financial market stability, play to the financial sector to promote economic development and stability as a whole. Micro level, the shares of each enterprise introduction clear reflect their own value, development potential and shareholder confidence in the enterprise, so as a barometer of business conditions, companies pay close attention to the volatility of the stock market. At the same time, a large number of investors in each country pay close attention to the volatility and trend of stock prices all the time, so as to ensure their investment can gain stable profits. Since the early 1990 s, China has established the Shanghai and Shenzhen stock exchange, securities industry has nearly 30 years of time, become the world's second largest market after the United States, hitting A record high in 2017, A total stock market value, reached 56.62 trillion yuan, an increase of $11.85 \%$ over the previous year; At the same time, the overall valuation of the a-share market continued to decline, with the price/earnings ratio dropping to 16.5 times from 18.54 times last year. China's capital market is entering a new stage of development. With the continuous development of economy, financial market scale and transaction scale are also expanding. Development also has a lot of problems at the same time, compared with the developed countries of Western Europe and the Americas, China's stock market has a lot of problems, such as cannot correctly understand and measure market risk or insufficient understanding of risk, not only will reduce the efficiency of asset allocation in the economic and social activities, increase the economic running cost, also due to the wrong without scientific research market, causing investors suffered huge losses, which affects the healthy development of social economy and even induce panic, etc. Therefore, it is of great theoretical value and practical significance to study the characteristics of China's stock market price and volatility, and provide good advice to decision-makers and shareholders. 


\section{Literature review}

\subsection{Theoretical research status}

The initial theoretical basis for the study of stock market volatility is modern financial theory. In the 1950s and 1970s, modern financial theory had an unshakable position in the whole field of financial market research. The important features of this theory are random walk theory and efficient market hypothesis. The so-called random walk theory is refers to financial markets, stock prices and yields are unpredictable, random walk process is not affected by other factors, there is no rules to follow, and the important premise of this theory is the efficient market hypothesis. Scholars, according to the study found that the stock price can reflect the market information and effective information to differentiate according to the market, the market is divided into effective market, half strong and effective market and the weak efficient market, the efficient market hypothesis, the price of the stock market at present, reflect all market information, information is completely free flow between different groups, no one can rely on its own information gain additional benefit from the stock market. But with the continuous development of econometrics and perfect, the scholars in the empirical study found that long memory phenomenon in financial time series, calendar effect, spike thick tail, the phenomenon such as volatility smile poses challenges to the traditional financial theory, is no longer before the assumed sequence of random walk. In the face of the "abnormal phenomenon" in the financial time series, the new financial theory based on noisetrading and sharing market hypothesis has gradually become the theoretical basis for studying stock market volatility. The new financial theory firstly negates the hypothesis that the market is completely efficient. Not every consumer has all the information, nor is every consumer completely rational. So the stock market volatility, will certainly be affected by many man-made factors, not random walk sequence, a new theory of financial development, for scholars to research the stock volatility characteristics provides a theoretical basis.

\subsection{Empirical research status}

In empirical research, the research on volatility of the stock model, is one of the earliest Engle (1962) proposed by autoregressive conditional heteroscedasticity $(\mathrm{ARCH})$ model, pioneered the describe the characteristics of the time series variance changes over time, is a breakthrough in the field of empirical studies of financial time series. The biggest characteristic of ARCH model is that it does not assume that the variance of error term is random, but changes with time. Bollerslov (1986) on the ARCH (P) model, on the basis of joining distribution lags behind, thus put forward generalized autoregressive conditional heteroscedasticity (GARCH) model, the ARCH and GARCH model is raised, the later scholars on the basis of continuous development and innovation, the formation of volatility of the most popular research field of the ARCH model. In addition to the family of the ARCH models, Talyor (1986) put forward the model of stochastic volatility (SV), SV model is widely used in stock price fluctuations, today, the SV model has become a popular model, the study of financial time series good depict the spike thick tail, volatility of financial time series cluster, long memory, etc. Wang (2003) study of the Chinese stock market using R/S analysis of long-term memory, he concluded that the characteristics of the Chinese stock market does not agree with that of other countries, both the long memory characteristic, and have a short memory. Fan (2016) took Shanghai stock market as the data to study the herd effect of the stock market, and analyzed the time point and degree of influence of the herd effect and other factors. Yang (2016), based on the data of 2013.1.1 -- 2015.12.31, analyzed the reasons for the fluctuation of China's stock market and made the prediction of the later volatility. Zhang (2018), 5 minutes to the Shanghai index data as the research foundation, to study the volatility of China stock market whether there is a long-term memory and structure mutation, study the influence of structural breaks of volatility long-term memory and to mutation sequence whether still have long-term memory. In this paper is focused on in the hang seng index in Shanghai for 11 years of price data for research, analysis of the stock's closing price and yield fluctuation characteristics, find out the cause of the volatility, and to maintain financial market stability and security gives the corresponding policy recommendations.

\section{Descriptive statistics of stock market closing price and return rate}

\subsection{Descriptive statistics of stock market closing price}

The data source of this paper is the closing price of the Shanghai composite index, and 2,526 data were selected from December 31, 2007 to March 28, 2008. The stock market price curve is as shown in Figure 1. 


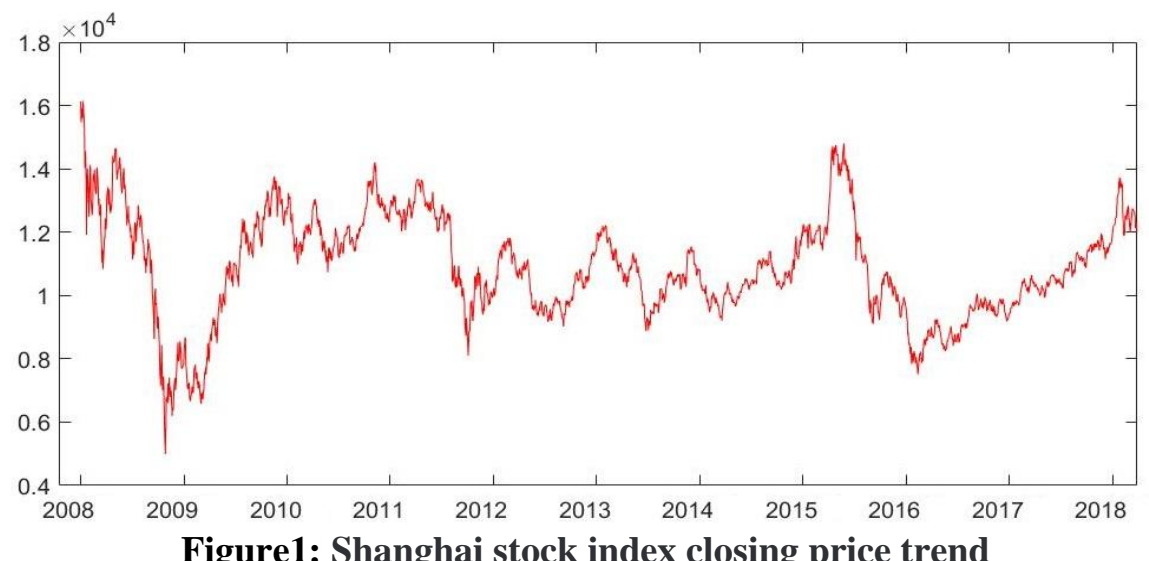

Can be found by observing the stock price chart above, the following three characteristics, through these characteristics, perhaps we can find the cause of China's stock market volatility, especially the cause of the big change.

1) in the past ten years, China's stock market has experienced great ups and downs, which is not a stable time series.

2) at several time points, the change of stock price suddenly appeared significantly, such as a sudden drop in 2008, 2010 rise obviously, fell in 2011, sudden rise in 2015, in 2016 began to slowly recover.

3 ) the average closing price of the stock market is around 1000, with the highest closing price reaching 1600 and the lowest reaching about 300, among which 2008 set a record low and 2015 set a record high.

\subsection{Descriptive statistics of yield volatility}

Volatility in the stock market is that in addition to study the simple price fluctuation and trend, more important is the study of the yield fluctuation, because the yield compared with the closing price, excluding some trend and seasonal factors, more can reflect the changes in volatility. When ordinary shareholders buy stocks, the main purpose is to obtain returns. Therefore, the yield fluctuation is also the focus of our research. The chart below shows the volatility of stock market returns, $r_{t}=\ln p_{t}-\ln p_{t-1}$.

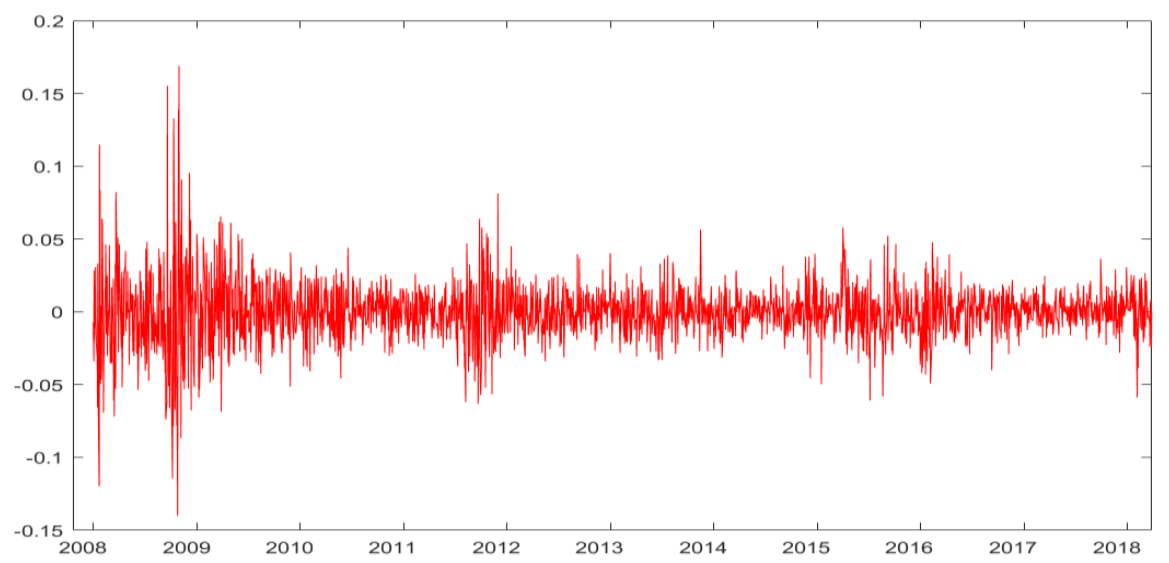

Figure2: Shanghai index stock yield volatility trend

By looking at the volatility chart of stock returns in the figure above, we can find the following characteristics:

1) the agglomeration of yield volatility, usually followed by large fluctuations, and small fluctuations followed by small ones. For example, in 2008, 2009 and 2011, the volatility was relatively large. In other years, the volatility was more uniform.

2) volatility is around zero, with the highest volatility at the end of 2008, followed by early 2008 and 2011. Just by graph, we can see fluctuations of integration, integration also reflect, change under the influence of early, late to increase research is scientific and accurate, the detection by GARCH effect, through actual data fluctuations take a look at whether there is a connection. Through the GARCH effect detection, we can observe the following two pictures. Figure 3 is the autocorrelation function graph of the next 100 periods, and Figure 4 is the partial autocorrelation function graph of the delayed 50 periods. 


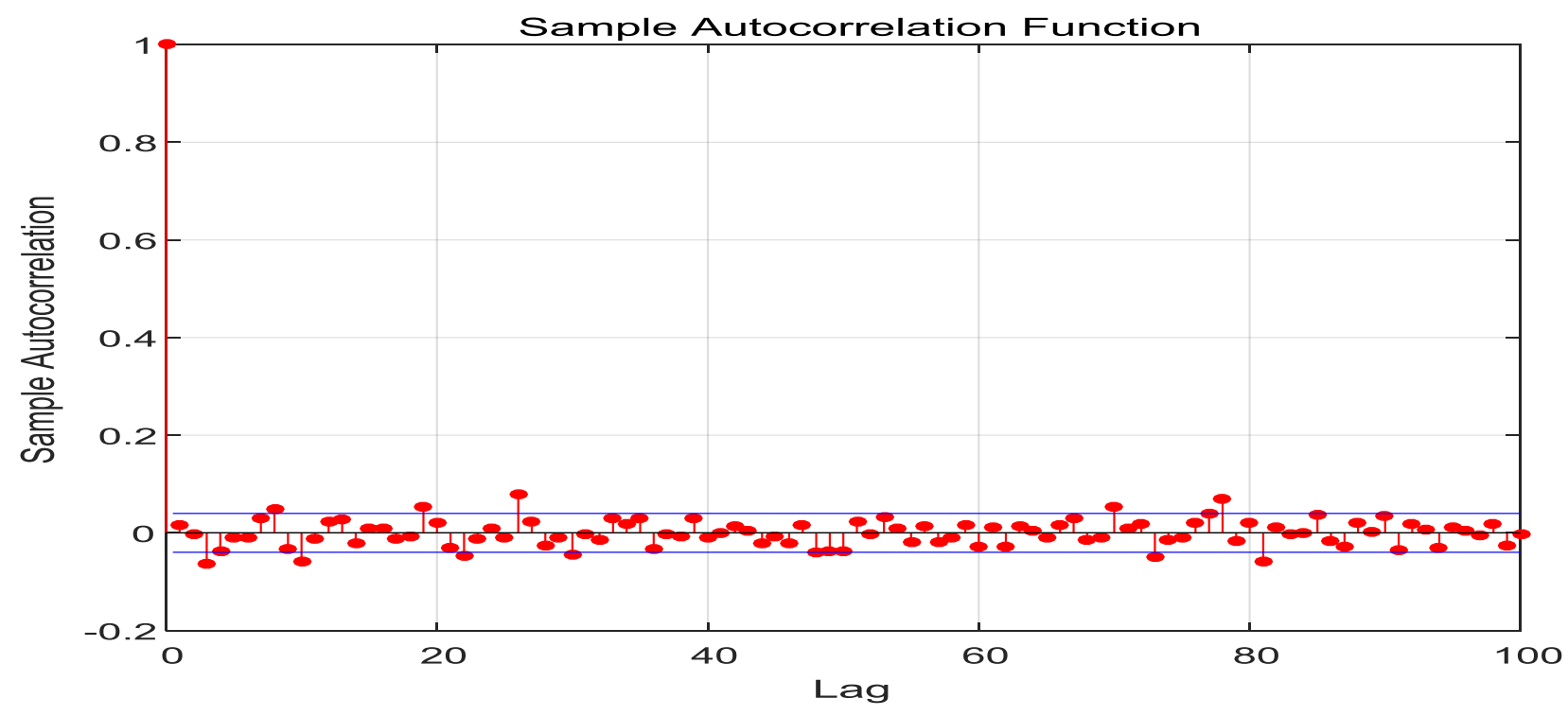

Figure3:ACF of Yield autocorrelation(lag100)

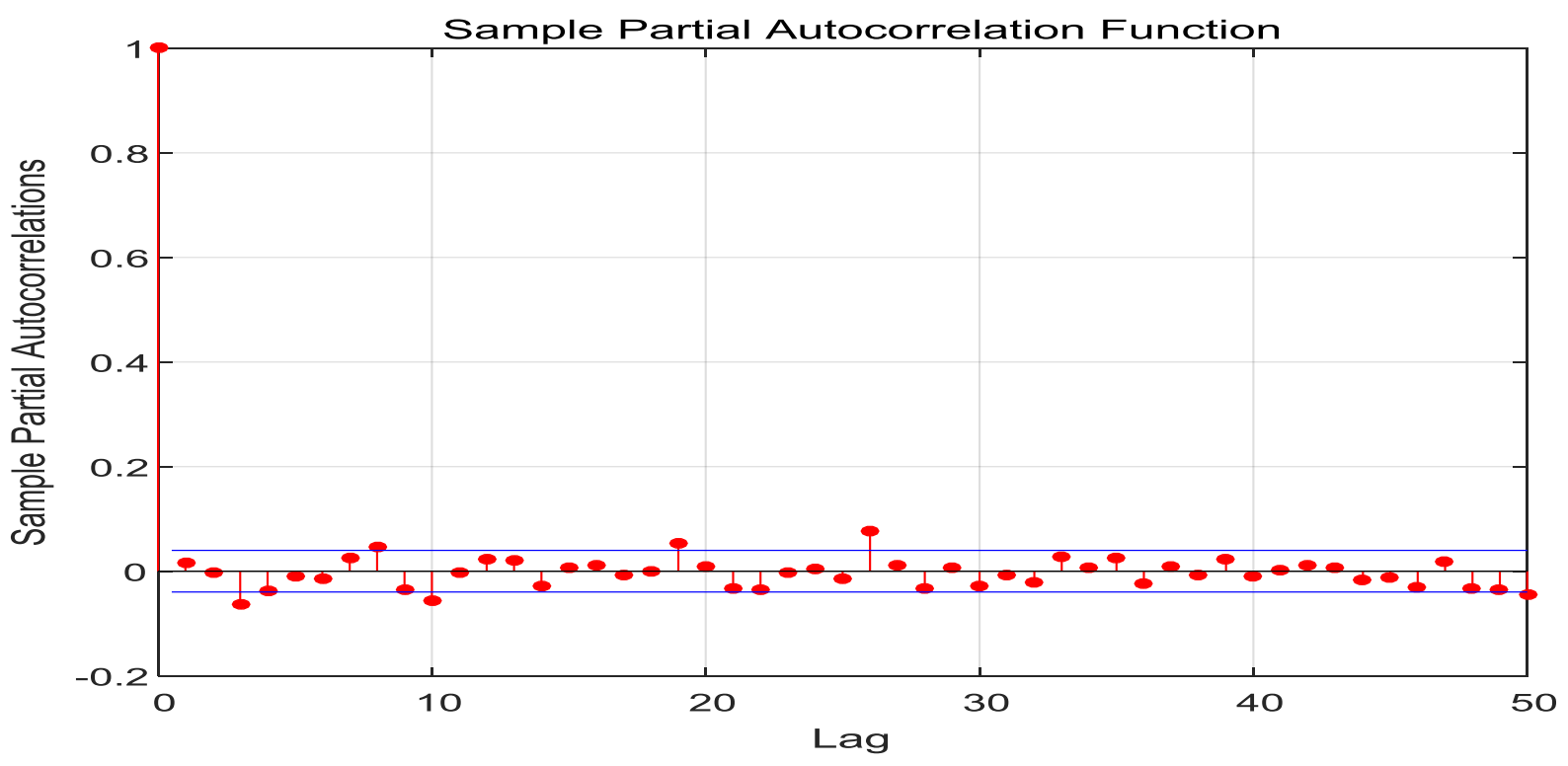

Figure4: ACF of Yield Partial autocorrelation (lag50)

By observing the autocorrelation function and partial autocorrelation function diagram, we can find that yield sequence has the very strong self-correlation, even 50 time, even after 100, the correlation coefficient is not zero, that is to say, after a long time, the yield size is still affected by the yield information before long. This feature is similar to long memory. One of the features of long memory is that the sum of autocorrelation coefficients tends to infinity. For the long-term memory study of financial time series, scholars have done a lot of work, there are many kinds of test methods and methods, this paper will not do more explanation. 


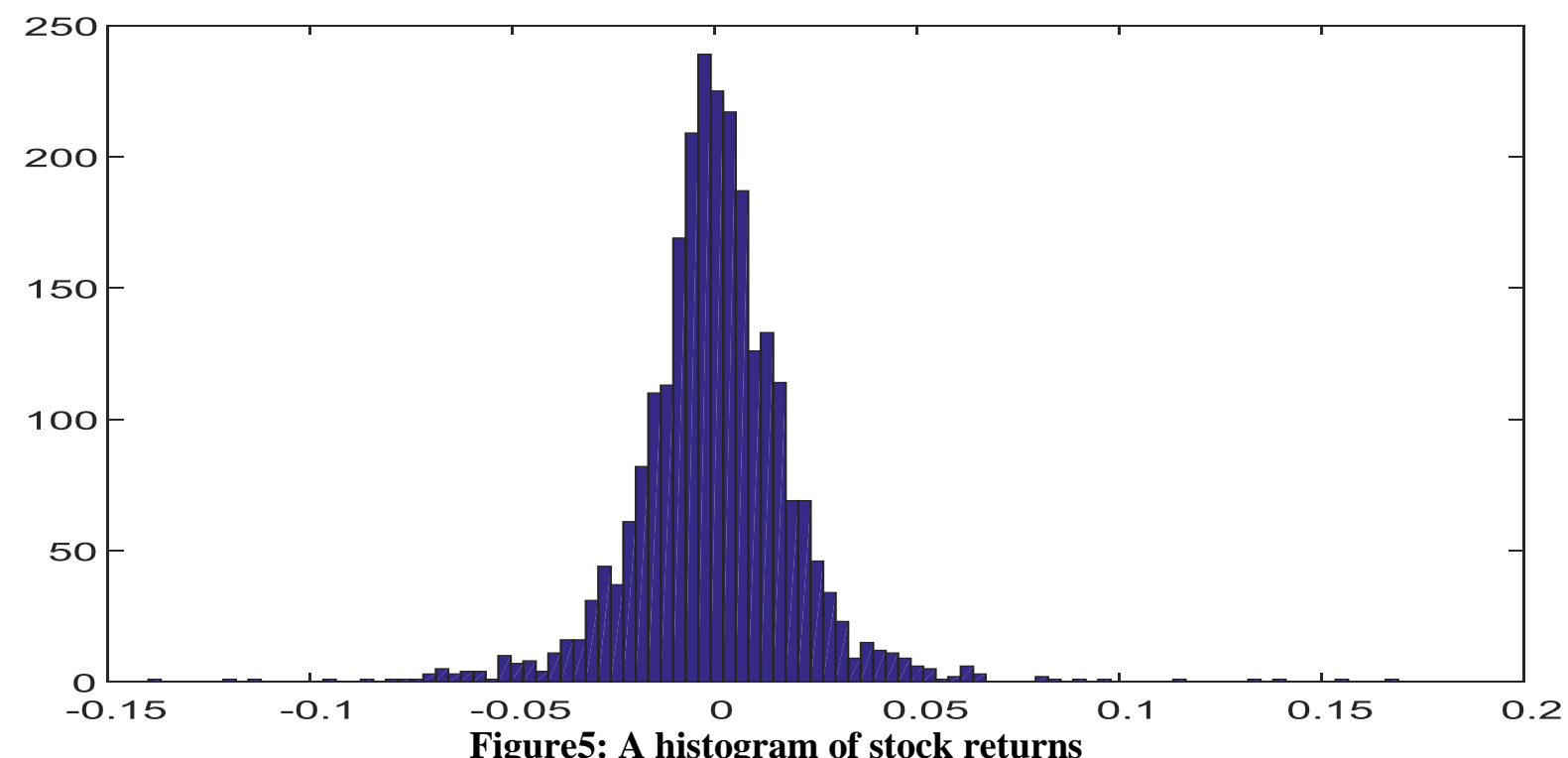

Above, yields the histogram, the histogram reflects the probability distribution characteristics of yield, from the above we can see that the stock yield fluctuation probability distribution similar to normal distribution, but is not a standard fall, compared with the standard fall, has the characteristics of back peak yield sequence. That is, when the rate of return is 0 , the probability is large, and the probability of the larger value and the smaller value of the yield is larger than the normal distribution of the positive mean. This reflects the characteristics of stock investment. From the perspective of large probability, returns are negative or negative. The above contents have proved the fluctuation characteristics of stock closing price and yield from theory and experience. First of all, volatility has agglomeration, and second, time points with especially large fluctuation are bound to be affected by some special factors.

\section{Factors influencing volatility of stock returns}

\subsection{Policy factors}

The domestic economic development level is the basic factor that determines the stock market, and the development level itself influences the social capital flow, the overall profit status of listed enterprises and the confidence level of shareholders. Reflect the influence the development of market and government behavior at the same time, as the regulation of financial markets, the government has been playing an important guiding role, the influence of any country in the stock market are given a policy. The government strongly support the development of a certain industry, the industry will continue to rise, stock price, in contrast, when the government legal policy limit one industry development, its share price is likely to decline. For the stock prices rose significantly in 2009, the main reason is that the October 30, 2009 officially kicked off the gem, the first batch of 28 stocks listed on the same day, refresh the record the history of China's stock market shares have been hit by more. On November 13, 2009, b-shares in Shanghai and Shenzhen burst into a wild surge, with a large number of stocks rising by the daily limit, while most b-shares without the daily limit rose by more than $7 \%$.During the period of rapid growth in March 2015, government departments issued documents to guide the deepening of institutional reform, accelerate the implementation of innovation-driven development strategy, and strengthen capital market support for technological innovation. At the same time, the people's bank of China announced a 1 percent cut in the reserve requirement ratio for all kinds of deposit-taking financial institutions. On this basis, the targeted implementation of targeted reduction measures. It can be seen that the two significant rises in the stock price index during the decade are related to policy factors.

\subsection{International financial market volatility}

Since China's entry into the WTO, China has become more closely connected with the world, and financial globalization has developed rapidly. Financial globalization strengthens the link between major economies tightness, effectively promote the economic development, but the financial markets closely related countries in the world at the same time, the fluctuation is also accelerating, opportunity and risk coexist, and the transmission speed than advantages of dangerous pass more quickly. 
As can be seen from figure 1, the stock price index dropped significantly in late 2008, for obvious reasons, the global financial crisis in 2008. The financial crisis and its very fast speed have been transmitted to China and caused great impact. It can be seen that the fluctuation of the international financial market has also affected the fluctuation of the Chinese stock market.

\subsection{Listed companies and investors}

The stock market is made up of several factors. The most important and fundamental part is listed companies and investors. First of all, it is well known that value determines price, and it is no exception in the stock market. The stock price of a listed company is determined by its value in the first place. Although the price often fluctuates, it is always around the value. The operating performance, profitability and development prospect of listed companies determine the expectation of investors, thus affecting the price fluctuation. Secondly, as a buyer in the stock market, investors influence the price trend through capital flow. The development of Chinese stock market is not very mature, number of individual investors is much larger than institutional investors, individual investors investment behavior is easily influenced by outside factors, at the same time, due to a serious asymmetry and conformity of confidence, leading to more volatile stock market in China.

\section{Summary and Suggestions}

From the above analysis, we can see that the Chinese stock market has a volatility agglomeration, and the volatility is affected by government policies, international market volatility and investors. Through the analysis of the characteristics of earnings fluctuation, the following three Suggestions can be given:

1) improve the information disclosure system of listed companies

Prices are first and foremost determined by value, and prices and yields, which are controlled by other factors, are irrational phenomena. Investors, however, are usually based on the financial statements of listed companies to observe the profitability and financial position of listed companies, so must prevent to increase the stock price of listed companies and providing false information, strengthen the information disclosure regulation, strengthen the penalties of false information, ensure the authenticity of information disclosure of listed companies, reliability and integrity.

2) strengthen investors' education

In China's stock market, due to the imperfect development, the number of individual investors is much larger than the number of institutional investors. Individual investors are vulnerable to the influence of information from all walks of life. They have poor ability to distinguish the authenticity of information and are highly emotional, which leads to increased volatility. Therefore, it is necessary to strengthen the training of investors, improve their information discrimination ability, and channel emotions. Reduce the behavior of investors to speculate maliciously due to personal emotion, and strengthen the strength of malicious investment.

3) improve the financial supervision system

Volatility index is an important index to measure market sentiment volatility, which reflects investors' expectations and information on stocks. It is regarded as an effective pressure gauge by financial institutions. From the point of the international market, before the economic crisis on the eve of the volatility index, always can predict in advance to the arrival of the volatility, volatility of visible system reflect more sensitive, so China's stock market also should strengthen the research on volatility index, to strengthen the supervision in advance of volatility. For each participation main body involved in the stock market at the same time, set up multi-level regulation system, ensure the stable development of all levels can be strictly guard against speculation and stock price manipulation, is the healthy development of stock market. This study was supported by the National Natural Science Foundation Youth project :"Research on the volatility of high-frequency data in Chinese finance based on discrete Fourier transform and periodic graph analysis" (\#71703177).

\section{References}

Engle R E. (1982). Autoregressive Conditional Heteroskedasticity with estimates of the variance of U.K. Inflation. Econometrica,50:987-1008.

Bollerslev.(1986). Generalized autoregressive conditional Heteroske-dasticity. Journal of Econometrics,(31):307327. 
RothschildEN.(1990). Asset pricing with a factor ARCH covariance structure: empirical estimates for treasury bills. Journal of Econometrics,(45):210-236.

Nelson D B.(1990). ARCH model as diffusion approximations. Journal of Econometrics,45:7-38.

Wang Z, Sun Y, Li P.(2014). Functional Principal Components Analysis of Shanghai Stock Exchange 50 Index. Discrete Dynamics in Nature and Society,1-7.

Cai J.(1994). A Markov model of switching-regime ARCH. Journal of Business and Economic Statistics, 12(3): 309-316.

Banerjee A, Urga G.(2005). Modelling structural breaks, long memory and stock market volatility: An overview. Journal of Econometrics, 129(1-2): 1-34.

Ariel, Robert A.(1987). A Monthly Effect on Stock Returns.Journal of Financial Economics, 18(1): 161-174.

Alvarez-Ramirez J, Alvarez J, Rodriguez et al.(2008).Time-Varying Hurst Exponent for Us Stock Markets. Physical-Statistical Mechanics and Its Applications,387 (24): 6159-6169.

Kokoszka P, Young G.(2017). Testing trend stationarity of functional time series with application to yield and daily price curves. Statistics and Its Interface, 10(1):81-92.

Yang S W.(2003). A study on the long-term memory of China's stock market earnings. Journal of systems engineering,22-28.

Fan F L.(2016). The research of herd behavior in Chinese stock market based on high frequency data. China, Guangxi university,35-39.

Zhang Y R,Tan Z X.(2018). Long-term memory, structural mutation and status identification of volatility in China's stock market. Journal of Southern finance,134-147. 